\title{
Erratum to: Energy efficient clearance routing in WSN
}

\author{
Devesh Pratap Singh ${ }^{1} \cdot$ R. H. Goudar ${ }^{2}$
}

Published online: 21 February 2017

(C) The Society for Reliability Engineering, Quality and Operations Management (SREQOM), India and The Division of Operation and Maintenance, Lulea University of Technology, Sweden 2017

\section{Erratum to: Int J Syst Assur Eng Manag DOI 10.1007/s13198-014-0263-0}

Unfortunately, the originally published article PDF was corrupted. Repetition of Figure 34 and blank pages were displayed at the end of the article PDF.

The redundant elements have been removed and the article PDF is updated accordingly.

The online version of the original article can be found under doi:10.1007/s13198-014-0263-0.

\section{R. H. Goudar}

rhgoudar@gmail.com

Devesh Pratap Singh

devesh.geu@gmail.com

1 Department of Computer Science \& Engineering (CSE),

Graphic Era University, Dehradun, India

2 Department of Computer Network Engineering (CNE),

Visvesvaraya Technological University (VTU),

Belgaum 590018, India 